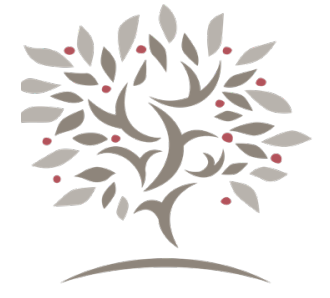

\title{
Revisiting Site Visits through the Lens of Disability Studies
}

\author{
Emily O. Gravett \\ James Madison University
}

\begin{abstract}
A B S T R A C T
The site visit (also called a field trip, excursion, or even field research) is a well-known learning activity in religious studies classrooms. In this article, I will analyze site visits to reveal how ableism is embedded even in educational practices common to religion courses. First, I will provide a brief overview of disability studies, various models of disability, and the pervasive ableism that structures higher education. Next, I will describe the typical conceptions and components of a site visit, as illustrated by real religion syllabi, with consideration of the barriers that it may present for students who "deviate" from the "norm." I will then introduce some principles of Universal Design and Universal Design for Learning, which may give readers ideas and tools for revising and expanding their assignments, including site visits. I will conclude with some (not definitive or exhaustive) ideas for making site visits more inclusive.
\end{abstract}

\section{KEYWORDS}

site visits, field trips, disability, disability studies, universal design, universal design for learning

\section{Introduction}

The site visit (also called a field trip, excursion, or even field research) is a well-known learning activity in religious studies classrooms, especially in introductory courses such as Religions of the World, which I teach every year. ${ }^{1}$ Like other place-based or community-based educational experiences (the latter of which are "highimpact practices" [Kuh 2008]), site visits can give students direct observation of and even participation in the religions that, otherwise, they may only have been studying at some remove, from their academic "armchairs." The firsthand experience of site visits is thought to "bring alive the study of religion" (Brodeur 2004). They can be risky, unpredictable, and exciting (Burford 2004). Ashcraft (2015) reports that a field trip to a Shaker village during his master's program led him to research on new religions and then became the guiding theme of his dissertation. He

1 I would like to thank my friends and colleagues at James Madison University, Daisy Breneman and Matt Trybus, for their continuing support and education in the areas of disability and disability studies. Without their patient and loving guidance, I would not have even thought to write this article, let alone had anything worthwhile to say. 
claims, "The experience of seeing, of being present bodily, was crucial to my transformation" (2015). Some instructors even require students to visit a site of a religion different than their own (if they affiliate with any), to provide further opportunity for encountering new communities; stepping outside of comfort zones; complicating stereotypes, negative impressions, and/or inevitable biases; building empathy; honing ethnographic and reflective skills; collecting data; illustrating insider/ outsider distinctions; practicing religious etiquette; acquiring religious literacy; and making connections between learning in the classroom and the so-called real world outside of it. Site visits have the potential to "rattle ... students' cages" (Ashcraft 2015), making the strange seem familiar and the familiar seem strange, which is something that religious studies does at its best (Muesse 1997).

In writing about site visits within our field, experienced instructors have been generous in offering advice to others who wish to integrate this activity into their own courses. Indeed, the entire October 2004 issue of Religious Studies News was devoted to the topic. Such advice tends to focus on the "nuts and bolts of site visits" (Burford 2004). There are certainly logistical and legal details for instructors to consider. For instance, Hussain (2004) reminds us to make contact with the site about the impending volume of student visits, to work with the institution's risk management office to complete the proper documentation, and to arrange for campus transportation to take students to the site. And, of course, students need to be advised on what they might expect from the visit, as well as proper courtesy and conduct. Ashcraft (2015) shares that he tells his students to "keep an open mind," "be respectful," "ask questions," "listen and observe," as well as "participate only as much as you feel comfortable, based on your own understanding of what comfort is." While considerations of race and/or gender sometimes emerge in these discussions (such as, will all genders be welcome in all spaces at the site? will some students need to dress or cover up differently than others?), analogous considerations of disability do not. (Notably, in her list of potential reasons not to do a site visit, Burford [2004] does not mention questions or concerns of access.) Nor is there explicit mention that religious traditions have conceptualized disability-in their sacred texts, in their ritual practices, in their hierarchical social models-in limiting, even pejorative, ways (Schumm and Stoltzfus 2016), just as occurs with the sexism, colorism, and other forms of marginalization and discrimination from which religions are not immune. For a student with a disability (who, of course, also holds other social identities), these conceptions could make site visits an especially difficult, triggering, or hurtful experience. This inattention to disability, while unfortunate, does align with broader trends in higher education and society at large; disability is so often invisible and ignored, even though people with disabilities are the largest minority group in the US (United Nations n.d.). Site visits, like so many of our other assignments, are undergirded by implicit presumptions of a singular, "normal"-that is, non-disabled-student.

But we know that our student populations are no longer homogenous (if they ever really were). Past conceptions of the normal or typical student (that is, white, wealthy, non-disabled, cis-gendered, heterosexual, Christian, male)-and generic approaches for how best to teach him-no longer hold in increasingly diverse classrooms. (Even the notion of "average" is coming under scrutiny [see Rose 2016].) More women than men now attend college (Marcus 2017) and many projections, based on US census data, have whites in the minority in our country in just a few decades (Passell and Cohn 2008). According to the US Department of Education (2016), over 10 percent of undergraduates report having a disability, although even that figure is likely low, given the numerous impediments to disclosure (for example, getting an expensive diagnosis from a medical professional in order to provide appropriate documentation to an office of disability services in the first place; see, for instance, Toutain [2019]). What we do know is that there will be students with disabilities, visible or invisible (Disabled World 2019), in all our classes, whether-and this is important-we know it or not. As Rose says, variability is the rule, not the exception (2012). As a result, it is time for us to reexamine site visits through this lens.

In this article, I will analyze site visits to reveal how ableism is embedded even in educational practices common to religion courses. First, I will provide a brief overview of disability studies, various models of disability, and the pervasive ableism that structures higher education. Next, I will describe the typical conceptions and components of a site visit, as illustrated by real religion syllabi, with consideration of the barriers that it may present for the variety of students who deviate from the norm. I will then introduce some principles of Universal Design (UD) and Universal Design for Learning (UDL), which may give readers ideas and tools for revising and expanding their activities, including site visits. I will conclude with some (not definitive or exhaustive, admittedly) ideas for making site visits more inclusive. Through a discussion about this particular assignment, I hope to call religion instructors' attention to disability more generally, so that we may become more aware of the inadvertent ways our assignments may exclude and so that we may better appreciate, leverage, and respond to the rich diversity of the human experience, in our classrooms and beyond. 


\section{Disability Studies}

As I have written elsewhere with colleagues expert in disability (Trybus, Breneman, and Gravett 2019), ${ }^{2}$ disability studies is an interdisciplinary field with a rich history and diverse scholarship (for example, Burch and Rembis 2014). It works to expose and increase awareness of ableism, defined by Liebowitz $(2017,153)$ as "the system of oppression that faces disabled people in our society, a system that marks disabled people as inferior and most importantly, other.... Ableism is dictating that there is a right, a 'normal' way to be, and disabled people aren't it. . . Ableism is a world that is centered on the nondisabled, instead of being welcoming for everyone." Ableism is pervasive, insidious, and-like sexism or racisminvisible to many of us, especially those of us who identify with the dominant groups who hold power (Tatum 200o). We are all complicit with ableism, to some extent, because we live in (and may even benefit from) a world that privileges the abled. This does not, as Liebowitz underscores, make any one of us "a horrible soulless person"; rather, "being an ableist just means that you have privilege you need to acknowledge, and patterns of thought that you need to change" (2017, 155). The work of disability studies scholars is to remind us of the constructed nature of identity and to call attention to the arbitrary designations of certain differences as deviant, while everything else is normal, typical, and good.

Yet disability, like gender or race, is a fluid, not a fixed, concept. This fluidity is reflected in the various ways it has been defined. No singular definition is accepted by everyone; some disability scholars (for example, Linton 1998) even eschew offering a succinct or pat definition of the term. Legally, in the US, the Americans with Disabilities Act or "ADA" (2008) defines disability as: "with respect to an individual $(A)$ a physical or mental impairment that substantially limits one or more major life activities of such individual; (B) a record of such an impairment; or (C) being regarded as having such an impairment." This definition situates the "problem" (and it is perceived as a problem, indicated by language like "limits") of disability with individuals and their lack of access to legal rights. This understanding of disability has certainly been beneficial in providing some legal advances and protections for a vulnerable population. And, practically speaking, institutions and their instructors must be aware of the legal ramifications (such as lawsuits) of failing to provide access. Yet legal models do not fully account for justice for people with disabilities.

What are called "medical" models of disability have also failed to provide full or useful accounts of disability, as my colleagues and I have previously written (Trybus, Breneman, and Gravett 2019). Early approaches to studying and navigating disability (especially in applied fields) pathologized it, focusing on the individual diagnosis as a deficit, with the goal being a cure. For many readers, "disability" may still conjure discrete medical or psychological conditions like Autism, Down syndrome, or color blindness. This is how I used to conceive of disability. Yet approaching disability solely from a medical perspective is restrictive (and abdicates responsibility) because it construes difference as an individual's “problem," like the legal model, as opposed to society's or the environment's (Linton 1998, 132-156). Moreover, this problem should ideally be resolved for the individual to be considered healthy, whole, and acceptable.

Conversely, social models of disability recognize the construction of disability as an oppressed and marginalized category of identity and locate the "problem" of disability not with individuals, as in the medical model, but rather with physical, social, and even rhetorical spaces. That is, it is an inaccessible environment and an exclusive, alienating society that is disabling-that creates disability-not any particular individual's medical diagnosis, difference, or so-called "impairment." The responsibility of creating more accessible environments thus becomes everyone's, not solely the burden of those individuals affected. Despite the benefits of social models, disability scholars like Siebers (2008) have argued that they, too, can fail to fully capture the lived experiences of people with disabilities. After all, even if it were possible to create totally inclusive and accessible environments (and it isn't), various impairments can still cause pain, frustration, and limitation. Many people with disabilities do wish for their symptoms to be erased or remedied (Jubilee 2019). As Shakespeare notes, a weakness of the social model is "the neglect of impairment as an important aspect of many disabled people's lives" $(2013,217)$.

2 Much of the material of this section was originally written in collaboration with Matt Trybus and Daisy Breneman for an earlier article on disability studies, in which we also described the field and the various models of disability. Scholars like Mr. Trybus and Ms. Breneman are particularly attuned to and accepting of scholarly connection and interdependence; as a result, both were supportive of me reiterating some of our important points here for a new audience. For comparison, readers may turn to our co-authored article, cited throughout this section. 
Newer, interactional models of disability seek to combine these previous models. They understand disability as the result of the interplay between an inaccessible environment and society, as in the social models, and an individual's particular impairment(s), as in the legal and medical models (Trybus, Breneman, and Gravett 2019). This combination recognizes that experiences of barriers arise from the interaction, with each side contributing. As such, these models focus on holistic strategies for fostering access, autonomy, and choice. It is not enough to create after-the-fact accommodations or narrow points of access, and we cannot dictate or assume others' needs. Rather, people with disabilities should be consulted (think of the adage "nothing about us without us" [Charlton 1998], or even, more plainly, "nothing without us") in the proactive design of inclusive spaces and learning environments and in the creation of multiple options for meaningful access and equitable engagement.

\section{Site Visits and Their Potential Barriers}

Obviously, site visits are not the only assignments given in religion courses. To help students learn, my colleagues and I routinely lean on readings, quizzes and exams, lectures, discussions, online polls, videos, research papers and reflective writing, and more. Part of the point of this essay is to use an analysis of the site visit assignment to increase our awareness more generally of disability, such that we may apply these insights to other elements of our instruction. Site visits provide an apt example of the ableism that, I contend, permeates our pedagogy.

For those unfamiliar, site visit or other similar ethnographic assignments in religion classrooms typically entail, as the name implies, students going on at least one trip to a religious site in the local area. They may do so alone or, more commonly, are asked to work in groups. Students are usually asked to provide some kind of reflection or report after the visit, for instance, comparing what they have witnessed or experienced during the visit to what they have learned about that religion from their readings or other course materials in the class.

Site visits may be presented as part of the course requirements, as we see in the following two excerpts from real religion syllabi:

You will be required to complete a fieldwork project for this course. The project consists of several parts including two site visits, a web analysis, an interview, and a 6-8 page reflection paper which summarizes your findings. (Narayanan 2017)

The final project takes place outside of the classroom entirely; it requires you to attend religious services/meetings and to interact with members of a faith tradition unfamiliar to you. You may do this either on your own or in small groups. This project requires a high degree of self-motivation, planning, coordination of schedules, and, if you desire, group work. After completing the off-campus portion of the final project, you will then write a paper. (Mathewson 2016)

Yet a question emerges from this sort of presentation. When site visits are articulated as part of the course requirements on a syllabus, what recourse or latitude might be available to a student who is unable, for whatever reason, to participate? These particular syllabi do not go on to note comparable alternatives or explain how a student could proceed if the site visit is untenable. It is also not always clear, from syllabi alone, how the site visit might contribute to specific student learning objectives, which could potentially be fulfilled in other ways, as I will discuss below.

Indeed, many religion syllabi do not elaborate on the site visit assignment; it is, rather, mentioned briefly and casually. For instance, in Hardy's syllabus (2014), under a section on "Field Assignments," students are told that they should "keep a journal of their experiences at places of worship at sites throughout the voyage. They will write a paper of 5-6 pp. on one of the major religions based on their field notes and reasearch [sic]." No other information is provided, though this assignment seems significant (that is, plural "experiences" at multiple "places" of worship, followed by a paper entailing outside research). Wiersma (2009) explains, within the "Reflection Essays and Learning Assessment" portion of the syllabus, that the "reflection essay will cover lecture material, and/or reading from the previous weeks and/or your impressions gained from our site visits." Though two appear on Wiersma's course calendar, the site visits themselves (such 
as what they entail, how they are graded, what purpose they fulfill, and so forth) are not described further. Of course, this brevity is not especially surprising. Instructors routinely supplement their syllabi with verbal commentary or more detailed written instructions (for example, handouts or information provided via the learning management system) that provide elaboration on important assignments. I do so myself; otherwise, my syllabi would be twenty-five pages! Yet we must also recognize that the syllabus is one of the first and most important communications that students receive about a course (as well as the person teaching the course), including how accessible and inclusive it will be. If students with disabilities see such requirements on the syllabus-and only receive additional information at some future point-it may be too late.

Other religion instructors do provide detail about site visits, even on their syllabi, though these details do not necessarily make room for the inevitable classroom diversity that disability epitomizes. Some tell students how to prepare for the site visit(s), for instance, by reading How to Be a Perfect Stranger: The Essential Religious Etiquette Handbook (2011). Others offer advice for what to do once students are on site. Henderson (2015) advises, for example: “Participate, don't simply observe. If everyone stands (or sits or kneels), you should, too." (As an aside, this particular advice may be risky to give students in a religious studies course; in some contexts, for instance, Native American sweat ceremonies, it is considered inappropriate and even offensive for outsiders to participate. Presumably, part of the in-class instruction would entail specifics about the individual religions, including their rituals and what sorts of participation, if any, would be welcome.) Yet site visit descriptions can reveal subtle barriers for students with disabilities. Henderson's above written instructions (2015), for instance, presume that her students will all be able to stand or sit or kneel, which may not be the case. (This is, in fact, one limitation of all physically active learning exercises; see Gravett [2018].) Other site visit assignment requirements presume that all students will be able to see what is happening on site or will be able to take notes, either by hand or with a device. Prohibiting the use of recording devices or laptops for taking field notes, which many site visit assignments do, may further hinder students for whom such technology facilitates their learning. (Indeed, one of the most requested accommodations at my institution is that of a note taker.) All syllabus descriptions presume that it will be easy for students to get to, into, and around the religious sites in the first place.

In fact, the very sites of site visits will likely be inaccessible in a variety of ways, even if they are technically ADA compliant (and, it is important to note that older buildings are not, necessarily). Religious sites are frequently punctuated by loud, unexpected, and (to many visitors) unfamiliar noises-from gongs to organs to bells to human chanting-yet these sounds could be jarring, disorienting, or even episode-inducing for some people. The same with strong smells, like incense, flowers, candles, or food. Forced interactions with, or even just the presence of, large groups (of people at the site) may interfere, for some students, with focused observation or comfortable participation. Moreover, many sites contain narrow entrances or aisles, multiple stories or levels, poorly arranged or designed seating, or rough and uneven surfaces. There is a Buddhist retreat center about an hour away from my institution, for example, which provides a nice opportunity for site visits, but the tour requires easy, free movement across sprawling natural spaces and in between detached buildings. If you are a person who uses a wheelchair or orthoses (braces), what would/could your participation in this site visit look like? Or, to take another example, a student in my recent Religion and Disability course realized that, in the church that he chose to study, the congregation had to walk down a long aisle and up a set of steps to arrange their bodies on very uncomfortable kneelers in order to receive the Eucharist; the minister went over to others who were known to need special consideration. If participation is encouraged by site visit assignments, we must ask, who is being left or singled out?

Requiring activities like site visits may have potentially deleterious effects for students with disabilities, even if inadvertent. This is, in part, why I have been hesitant to require such assignments myself, though I am also convinced of its great potential. Such requirements may encourage students with disabilities to avoid or drop the class entirely, if they get the sense from the syllabus that they will not be able to complete a major assignment in the course (and if there is a sense that there is no flexibility in how they might otherwise gain or demonstrate the knowledge associated with the visit). Students with disabilities may be implicitly encouraged to try to "pass" as a non-disabled person or to "cover" their disability (Linton 1998), so that they can participate in a site visit and its accompanying assignments, like the rest of the students. Or they may be forced into "outing" themselves or disclosing their disability, in order to ensure their full inclusion and participation, when they may have preferred not to share this information (then or ever) with the instructor and/or with their peers. 
One way or another, this sort of required assignment runs the risk of exacerbating feelings of overwhelm, anxiety, depression, loneliness, and exhaustion, as well as disempowerment, discouragement, debasement, insecurity, and isolation, that we know students with disabilities already experience in college. Notably, students with disabilities have reported feeling disempowered and discouraged specifically by instructors who lack basic knowledge about disabilities or accommodations, including those who do not believe such students even have disabilities (Francis et al. 2019, 253 ). 3 Site visits may, unintentionally, "other" or stigmatize individuals and reinforce the invisible but pervasive ableism that students (and instructors) with disabilities encounter routinely in academia (Dolmage 2017)-and society, more broadly.

\section{Universal Design/Universal Design for Learning}

So, what can we do? How can we work toward providing equitable access to all experiences and knowledge for everyone in our classes? How can we retain or try out site visits if we so desire? We need not simply discard the site visit, especially if it is already been working well for us. If we did that with every assignment or activity that we realize is potentially ableist, I fear we would have nothing left in our teaching toolkit! Thus, it may be helpful to familiarize readers with universal design approaches at this point. These are not quick fixes or simple checklists to make our learning environments inclusive, once and for all. Rather, these approaches can guide our intentional design of courses and individual activities, like the site visit, by giving us questions and principles to consider in advance and along the way.

From the outset, it is important to note that there are many related terms and frameworks in circulation, including "universally designed teaching," "universal instructional design," "universal design for instruction," and "universal design of instruction" (for further detail see Burgstahler 2015, 34-44). The most relevant for our purposes here, however, are universal design (UD), which focuses on building inclusive products and physical environments, and universal design for learning (UDL), which focuses on helping learners access and represent knowledge in multiple ways. There is obviously some overlap between the two, as we will see.

Emerging from the architectural world, UD advocates for designing environments, including educational ones, to be "welcoming and useful to groups that are diverse with respect to many dimensions," including disability; these environments should be usable, accessible, and inclusive to the widest spectrum of users (Burgstahler 2015, 3, 15). It is a proactive position, not a reactive one (for example, not only after an individual has gone through the burdensome process of disability disclosure). In UD, for example, individual students with disabilities are not expected to adjust to inflexible learning environments; rather, the environments are to be designed for the needs and preferences of anyone, to the benefit of everyone. A familiar example of UD in space is the curb cut. Curb cuts not only increase access to a building or a sidewalk/street for someone using a wheelchair-as we might initially perceive-but also for people pushing baby strollers or food carts, people on crutches or with walkers, people lugging suitcases, people riding on scooters, and so forth.

Of the seven principles of UD described by Burgstahler, four seem especially relevant to our considerations here, in the context of site visits: equitable use, flexibility in use, low physical effort, and size and space for approach and use (2015, 15-16). "Equitable use" means that "the design is useful and marketable to people with diverse abilities." Guidelines for this principle include providing the same means of use for all users (identical whenever possible, equivalent when not) and avoiding segregating or stigmatizing any users. With "flexibility in use," "the design accommodates a wide range of individual preferences and abilities," providing choice in methods of use and adaptability to the user's pace. "Low physical effort" is when "the design can be used efficiently and comfortably, and with a minimum of fatigue." Included in the guidelines for this principle is the minimization of sustained physical effort. The principle of "size and space for approach and use" includes the recommendation to "provide a clear line of sight to important elements of any seated or standing user" and to "provide adequate space for the use of assistive devices or personal assistance" (15-16). We can keep each of these principles in mind as we design and assess all our learning activities, not only site visits.

3 Alternatively, students in this study found great support in instructors who moved beyond the requisite accommodations and who were caring, warm, fun, and understanding (Francis et al. 2019, 253). 
Similarly, UDL recognizes "the need to make education more responsive to learner differences" (Meyer, Rose, and Gordon $\mathbf{2 0 1 4}, 5$-differences that are predictable and normal. We can "plan for expected variability across learners and provide curriculum that has corresponding flexibility" (10). Further, Meyer, Rose, and Gordon emphasize, “instead of seeing variability as problem, we now understand it to be an actively positive force in learning for the group as a whole" (10). Variability can be viewed as an opportunity, not a burden. The three core principles of UDL are that we, as an instructors, provide multiple means of engagement (the "why" of learning), multiple means of representation (the "what" of learning), and multiple means of action and expression (the "how" of learning) for students (7). This emphasis on multiplicity across the three guidelines is in recognition of the fact that "there is no one optimal path or learning method in any subject or skill” (27). Indeed, as Rose has shown, quite convincingly, in The End of Average (2016), individuals-both in terms of their personality traits as well as their paths toward goals-are actually quite "jagged."

The three UDL guidelines touch upon areas of learning variability that could represent barriers or, in a well-designed learning environment and from a different perspective, opportunities (Meyer, Rose, and Gordon 2014, 110). In consideration of the first guideline, "multiple means of engagement," instructors can provide students with options for self-regulation, for sustaining effort and persistence, and for recruiting interest. An example of providing options for recruiting interest would be to optimize individual choice and autonomy in the learning process. In the second guideline, "multiple means of representation," instructors are encouraged to provide options for comprehension; options for language, mathematical expressions, and symbols; and options for perception. As an example of the latter, we might offer alternatives for auditory and visual information. For the third and final guideline, "multiple means of action and expression," instructors can provide options for executive functions, expression and communication, and physical action. An example of the latter would be optimizing access to tools and assistive technologies, such as a laptop for note taking.

To reiterate, universal design frameworks and approaches such as UD and UDL do not offer instructors simple or singular solutions to the kinds of teaching conundrums that the site visit represents. As Price writes: "Universal Design is not one specific procedure, nor a recipe for success" $(2014,89)$; "efforts must always be partial and engaged in a process of continual revision" (87). At its heart, a universal design orientation encourages iteration, experimentation, and verification with those on the periphery. There is no one right or definitive way to make the religious site visit assignment-or any other learning activity-fully accessible for all students. Admittedly, this can feel frustrating or confusing. Yet, guided by UD and UDL, religious studies instructors can realize that they have many options for creating more inclusive assignments and learning environments where no average user with a certain set of abilities is assumed, where it is possible for everyone to participate, and where no one is singled out or stigmatized.

\section{Some Ideas}

As we near the end, I would like to offer some ideas for improving the site visit assignment-with the hope that these ideas, or at least the spirit behind them, may transfer to how we think about and design other learning activities. Yet, given that UD and UDL are not intended to dictate specific solutions to complex teaching questions or challenges, this section will naturally be less developed or directive than the others. When creating access, there is not one right way.

To begin, it is always helpful to consider what student learning objectives any assignment (including site visits) fulfills. We often (perhaps due to the lack of pedagogical training in many graduate schools) create assignments and other activities without thinking too much about them, because they seem fun and innovative, or they were assignments we ourselves received back in school, or they were what our predecessors did, or they are now what's easiest for us to do. If it turns out there actually aren't any learning objectives associated with the site visit (or any other assignment under consideration), then take this opportunity to develop some. . . or rethink having the assignment entirely. After all, why have an assignment if it doesn't serve some purpose in advancing student learning? This kind of intentional alignment between course objectives and assessments is the hallmark of backward design (see Wiggins and McTighe 2005; Fink 2013), a process routinely recommended to instructors to better help their students learn. Think back to the list of reasons that instructors assign site visits which I summarized near the start of the article; many of those could be student learning objectives for a religion course-and none require a site visit to accomplish. 
Once there are learning objectives in place, it is important to recognize that there are usually many ways in which they can be fulfilled. Ideally, we would offer all students multiple means for accessing content and demonstrating their progress or mastery (Meyer, Rose, and Gordon 2014); the site visit would then become just one option, among many. Let us consider the site visit assignment whose primary purpose is to allow students to witness real religious practices. ${ }^{4}$ In this case, perhaps watching a documentary film or a homemade video could similarly suffice; my students, for example, have viewed recordings of puja or the Holi festival (from Hinduism) using YouTube videos in class. Or one could take advantage of resources such as the American Religious Sounds Project, and play sound for our students, like adhan (the call to worship in Islam) or Hebrew cantillation (OSU 2020). We could bring the site to the students by inviting an individual or group into the classroom, for example, to conduct a religious ceremony for observation or to answer questions about their own experiences and perspectives. One could leverage video technology like Skype, Zoom, or WebEx, so the religious individual(s) doesn't even have to make the trip to campus. Perhaps this is an exciting opportunity for us to explore virtual reality, in partnership with our libraries and/or instructional technology experts; there are virtual tours of religious sitesfrom the Dome of the Rock to the Sistine Chapel-already available online. Perhaps we could invite students, like one of my colleagues did, to gain first-hand experience by making food associated with specific religious traditions, like challah in Judaism. Perhaps we could bring religious art or artifacts for students to look at and even, if appropriate, touch; in my department, we have many such objects on display in our common area and instructors can borrow them to use in class. Or we could use some combination of the above, and more, to fulfill this learning objective.

Of course, if the intent of the site visit assignment is to fulfill a different learning objective or set of learning objectives, then other alternatives can be imagined. For example, Hussain (2004) took his students to visit a mosque in one course, for the purpose of showing them the architecture, because he had learned there had been some local opposition to its construction. This is obviously a different sort of site visit, with a different intent, than the one outlined above for the observation of real religious practices. With Hussain's objective, students could be given the option of looking at photographs of the site, if the visit itself was a barrier. The idea here, when guided by UD/UDL, is to proliferate options, rather than foreclose opportunity; the site visit need not be the only entry point into student learning.

Along these lines, we might do what one of my friends, a professor of Buddhism, does, which is to make site visits optional. In previous Tibetan Buddhism and Introduction to Buddhism courses, both relatively small, she arranged for students to take voluntary trips to nearby meditation and retreat centers. (Note that she is not trying to arrange these kinds of visits for multiple religions, as one might, for instance, in an introductory survey course; that approach has seemed untenable to her, in large part because of the amount of preparation and prior knowledge she feels that her students need to have in order to respectfully go into others' spaces and engage.) During these visits, her students have variously had the chance to take a tour of grounds and dorms, to do Question and Answer sessions with residents, to choose to participate in mindfulness meditation exercises, and to experience, in person, what they had only been reading and discussing in class, from a more analytical perspective. Her goal is to give students a vivid experience that they might actually be able to remember in five years: to be able to move in a distinct space, to see art, to smell incense, to hear tones, to really get a feel of the religious phenomena. As many as half of the students have chosen to come on these optional visits, and as few as two. My friend believes requiring these site visits would be difficult, for many reasons, but she is particularly attuned to equity and access along many axes (for example, socioeconomic status: some students may not have the time, money, or vehicle to be able to get to the site).

If, however, site visits are deemed a primary way for students to meet a particular learning objective(s) and it makes sense to require them, we can still do our best to at least ensure that the sites themselves are accessible, by doing advanced investigation. In consultation with an office of disability services, disability studies experts, and/or people with disabilities, instructors can scout and screen possible locations and provide a list from which to choose, rather than simply letting student groups decide randomly and on their own. (If instructors themselves have disabilities-and, of course, many do-their perspective on and experience with potential sites would be especially valuable.) To be clear, this would require the instructor to research and visit the sites beforehand, which is a good idea anyway. As with so much of our teaching, labor at the front end of an assignment prevents scrambling for adjustments and accommodations

4 I am grateful to my colleague Dr. Christie Kilby at James Madison University for drawing upon her own experiences with site visits to brainstorm many of these alternatives for this example with me. 
(which may require more work) later on. Realistically, if sites are limited in the local area and not all are fully accessible, then being clear with students upfront (for example, by providing detailed descriptions about the features of each site, including potential barriers), so that they can exercise choice about which to visit, goes a long way.

The site visit assignment, if integral to the course, provides a nice opening to have a discussion with students about disability, access, and inclusion. Many students, like many of our colleagues, are not aware of disability or disability studies; it certainly was not on my radar until a few years ago. Students may not realize the harm that can be done by casually using words like "crazy" or "wheelchair bound" in the classroom; they may not be aware of the history of American eugenics, institutionalization, and forced sterilization associated with disability that is a part of our shared heritage (see Dolmage [2017] for an important discussion of this past). They may not know that many disabilities are invisible, and that we cannot know much about a person (including other important parts of their identity) just by looking at them. They may not recognize that the impulse to help, pity, or find inspiration in people with disabilities is considered condescending and offensive to many in the community. These are but some of the many points of conversation about disability that an assignment like a site visit could prompt, even if briefly, in a religion course. And, for those thinking that these topics seem too far afield from the religious studies topics they teach, please remember that disability has always been part of the religious experience, and the religion classroom, whether we are aware of it ourselves or not.

\section{Conclusion}

Decisions about site visits, like all pedagogical decisions, will necessarily be context dependent, guided by the particular institution and department, the instructor's training and personality, the topic and level of the course, the student population, and more. As I hope is clear, I am not claiming to offer a one-size-fits-all solution. What is important is that all of us consider disability in advance when designing a site visit-or any other religious studies assignment-recognizing and trying to reduce the barriers it can create for student learning. I suspect we don't have a very clear idea of the sorts of barriers that site visits can present for students with disabilities because there may not be much intersection between those students and this kind of assignment, for the reasons I indicated above. It can be hard for us to know, unfortunately, without a specific individual calling our attention to a specific problem. As such, this assignment presents an opportunity for raising awareness, in students and in ourselves, about disability, and about the other kinds of diversity that inevitably exist in religious and even our own classroom communities. We can open ourselves up and actively seek out feedback and suggestions about this assignment or others, from students, colleagues, and community members with disabilities. It is in this way that we can engage in the continual process of reflection and revision-so important to universal design and to academia, writ large.

\section{B I B LI O G RAPHY}

ADA (Americans with Disabilities Act). 2008. Sec. 12102. Definition of Disability. https://www.ada.gov/pubs/ adastatute08.htm\#12102.

Ashcraft, W.M. 2015. “Field Trips in the Course on New Religions.” Religious Studies News, January 26. http://rsn. aarweb.org/spotlight-on/teaching/new-alternative-religions/field-trips-course-new-religions.

Brodeur, P.C. 2004. “Integrating Site Visits in the Pluralism Project at Connecticut College." Religious Studies News, AAR Edition (October). http://rsnonline.org/indexd966.html?option=com contentandview=articleandid $=544$ and temid $=625$.

Burch, S. and Rembis, M., eds. 2014. Disability Histories. Urbana, IL: University of Illinois Press.

Burford, G.G. 2004. “The Nuts and Bolts of Site Visits.” Religious Studies News, AAR Edition (October). http://

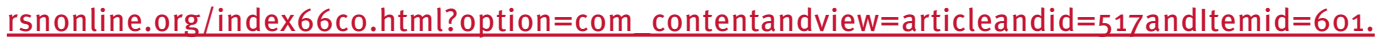

Burgstahler, S.E., ed. 2015. Universal Design in Higher Education: From Principles to Practice. 2nd ed. Cambridge, MA: Harvard Education Press. 
Charlton, J.I. 1998. Nothing About Us Without Us: Disability Oppression and Empowerment. Berkeley, CA: University of California Press.

Disabled World. 2019. Disabilities: Definitions, Types and Models of Disability. https://www.disabled-world.com/ disability/types/.

Dolmage, J. T. 2017. Academic Ableism: Disability and Higher Education. Ann Arbor, MI: University of Michigan Press.

Fink, L.D. 2013. Creating Significant Learning Experiences: An Integrated Approach to Designing College Courses. San Francisco, CA: Josey-Bass.

Francis, G.L., J.M. Duke, M. Fujita, and J.C. Sutton. 2019. "It's a Constant Fight:" Experiences of College Students with Disabilities. Journal of Postsecondary Education and Disability 32 (3): 247-261. https://files.eric.ed.gov/fulltext/

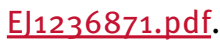

Gravett, E. O. 2018. “Response to 'Quick Fix: Get Up! Five Ways to Energize a Classroom with Physically Active Learning." College Teaching 66, 4: 211-12. https://doi.org/10.1080/87567555.2018.1495608.

Hardy, G. 2014. "Semester at Sea Course Syllabus.” http://www.semesteratsea.org/wp-content/uploads/2012/10/ Hardy RELG1559 WorldReligions.pdf.

Henderson, S.W. 2015. "Site Visit Guidelines to Places of Worship." Interfaith Youth Core. https://www.ifyc.org/sites/ default/files/resources/Henderson Site\%20Visit.pdf.

Hussain, A. 2004. Site Visit To a Mosque. Religious Studies News, AAR Edition (October). http://rsnonline.org/ indexcefd.html?option=com contentandview=articleandid=542andltemid $=623$.

Jubilee. 2019. “Do All Disabled People Think the Same?” Spectrum, Season 2, Episode 2. https://www.youtube.com/ watch?v=kaVkKQTTei8.

Kuh, G. 2008. High-Impact Educational Practices: What They Are, Who Has Access to Them, and Why They Matter. Washington, DC: Association of American Colleges and Universities.

Liebowitz, C. 2017. “Just Because it's Ableist Doesn't Mean it's Bad.” In Privilege: A Reader, edited by M.S. Kimmel and A.L. Ferber, 153-55. Boulder, CO: Westview Press.

Linton, S. 1998. Claiming Disability: Knowledge and Identity. New York, NY: New York University Press.

Marcus, J. 2017. "Why Men Are the New College Minority.” The Atlantic, August 8. https://www.theatlantic.com/ education/archive/2017/08/why-men-are-the-new-college-minority/536103/.

Mathewson, D. 2016. “Interfaith Site Visits + Self Analysis Paper: Final Project Assignment.” https://www.ifyc.org/ sites/default/files/resources/Mathewson\%20Final\%20Project.pdf.

Matlins, S.M., and A. J. Magida, eds. 2011. How to Be a Perfect Stranger: The Essential Religious Etiquette Handbook. Woodstock, VT: Skylight Paths Publishing.

Meyer, A., D.A. Rose, and D. Gordon. 2014. Universal Design for Learning: Theory and Practice. Wakefield, MA: CAST.

Muesse, M.W. 1997. “Religious Studies and “Heaven's Gate”: The Field's Role Is to Make the Strange Familiar and the Familiar Strange." The Chronicle of Higher Education, April 25. https://www.chronicle.com/article/ReligiousStudies-andHeavens/74974.

Narayanan, V. 2017. “REL2300: Introduction To World Religions.” https://religion.ufl.edu/files/World-ReligionsSyllabus-Fall-2017-002.pdf. 
OSU (Ohio State University). 2020. American Religious Sounds Project. https://religioussounds.osu.edu/.

Passel, J.S., and D. Cohn. 2008. “U.S. Population Projections: 2005-2050." Pew Research Center, February 11. https:// www.pewsocialtrends.org/2008/02/11/us-population-projections-2005-2050/.

Price, M. 2014. Mad at School: Rhetorics of Mental Disability and Academic Life. Ann Arbor, MI: University of Michigan Press.

Rose, T. 2012. "Variability Matters." Cyberlearning Research Summit, January 18, 2012. https://www.youtube.com/ watch?time continue $=3$ and $=8$ WCInViCEVM.

Rose, T. 2016. The End of Average: Unlocking Our Potential by Embracing What Makes Us Different. New York, NY: HarperCollins.

Schumm, D.Y., and M. Stoltzfus. 2016. Disability and World Religions: An Introduction. Waco, TX: Baylor University Press.

Shakespeare, T. 2013. “The Social Model of Disability.” In The Disability Studies Reader, edited by L. J. Davis, 214-221. New York, NY: Routledge.

Siebers, Toby. 2008. Disability Theory. Ann Arbor, MI: University of Michigan Press.

Tatum, B. D. 2000. “The Complexity of Identity: 'Who Am I?'." In Readings For Diversity and Social Justice: An Anthology on Racism, Sexism, Anti-Semitism, Heterosexism, Classism and Ableism, edited by M. Adams, W. J. Blumenfeld, H. W. Hackman, X. Zuniga, and M. L. Peters, M. L., 9-14. New York, NY: Routledge.

Toutain, C. 2019. "Barriers to Accommodations for Students with Disabilities In Higher Education: A Literature Review." Journal of Postsecondary Education and Disability 32 (3): 297-310. https://files.eric.ed.gov/fulltext/ E)1236832.pdf.

Trybus, Matthew J., Daisy L. Breneman, and Emily O. Gravett. 2019. "Ableism, Accessibility, and Educational Development: A Disability Studies Perspective." New Directions for Teaching and Learning 2019, Issue 158. https://doi.org/10.1002/tl.20339

United Nations. n.d. "Factsheet on Persons with Disabilities." Department of Economic and Social Affairs: Disability. https://www.un.org/development/desa/disabilities/resources/factsheet-on-persons-with-disabilities.html.

U.S. Department of Education. 2016. "Chapter 3: Postsecondary Education." National Center for Education Statistics Digest of Education Statistics, 2015. https://nces.ed.gov/programs/digest/d15/ch_3.asp.

Wiersma, H. 2009. "REL 358: Life and Work of the Church Syllabus." http://rsnonline.org/images/pdfs/SyllabiLifeandWorkoftheChurch-Wiersma.pdf.

Wiggins, G., and J. McTighe. 2005. Understanding by Design. Alexandria, VA: Association for Supervision and Curriculum Development.

\section{ABOUT THE AUTHOR}

Emily 0. Gravett is an assistant professor in the Department of Philosophy and Religion and an assistant director in the Center for Faculty Innovation at James Madison University. She earned her PhD in Religious Studies from the University of Virginia. 
